\title{
Identidades y nuevos conflictos
}

\author{
Gilberto Aranda y' Sergio Salinas
}

La globalización ha cambiado sustancialmente las pautas políticas, económicas y sociales con que la humanidad se ha movido durante los últimos 30 años. La integración de economías, el cambio acelerado, la revolución de las lecnologías hablan de un fenómeno antiguo annque cualitativamente distinto. Sin embargo, el proceso de intensificación de las interconexiones globales ha producido consecuencias que a veces aptuntan a direcciones opuestas: integración y fragmentación, homogeneización y diversificación, mundialización y localización.

Algunos de los resullados del proceso de globalización se han traducido en experiencias de debilitamiento estatal y fractura de sociedades. Este tiltimo caso se relaciona con el despertar de demandas identitarias basadas en la etnicidad, una cosmovisión religiosa, o el simple despertar de nacionalismos aletargados. El siguiente ensayo pretende repasar las premisas y' las clasificaciones que desde diversos ángulos teóricos explican la referida tendencia en la polílica mundial.

\section{INTRODUCCIÓN}

$\mathbf{H}$ ace un tiempo, Ulrich Beck, profesor de sociología de la Universidad de Munich, aseveró en un matutino español que "todo el mundo siente amenazada su identidad frente al poderosísimo rival que es la globalización"!
Esta afirmación nos enfrenta a una de las características principales del mundo actual, la dicotomía entre los conceptos de identidad y de globalización. Pero no son conceptos vacíos, solo con sentidos epistemológicos, sino que tienen expresión real en un nuevo orden mundial, en un

I Beck, Ulrich, "La cuestión de la identidad", El País, Madrid, 11 de noviembre de 2003. Señala el profesor Beck: "que hasta cierto punto nos sentimos expulsados de la patria, expuestos a los mortificantes peligros de la asimilación incondicional. Por consiguiente, en todas partes se intenta imponer indisimuladamente identidades nacionales, éınicas y locales". 
nuevo concepto de política y en nuevos conflictos que aún no podemos entender.

En ese proceso han incidido los alcances dispares de una globalización que deviene tanto en desarrollo económico como en ausencia del mismo. La marginación de ciertos grupos sociales de las principales corrientes de desarrollo, unicla a la pauperización de sus condiciones de vida, han provocado la canalización de sus demandas bajo un formato identitario premoderno. En consecuencia, la globalización pasa a convertirse en factor que incide en la reafirmación de ciertas identidades que cuestionan abiertamente su adhesión a una sociedad nacional.

\section{Una vorágine de cambios ha provocado fuertes cuestionamientos de los} paradigmas tradicionales.

Lo anterior también se relaciona con el hecho de que todas las sociedades han sido y están siendo sometidas a profundas transformaciones, vertiginosos cambios que incluso han puesto en cuestionamiento nuestros tradicionales paradigmas. En pocos años hemos visto transformaciones que antes tomaban siglos. Este escenario hace que se vislumbre un cambio cultural cuyo motor y principales factores de cambio son la economía global y las nuevas tecnologías de información y de las comunicaciones.

Estas transformaciones, la comprensión de su naturaleza, su alcance y sus consecuencias, han sido desde los años setenta una de las preocupaciones principales de las Ciencias Sociales. Muchos autores de las más diversas disciplinas han preparado cientos de libros y artículos intentando analizar los cambios que acontecen en nuestras sociedades ${ }^{2}$. Pero esta nutrida bibliografía trasunta un problema de fondo: es que son visiones particularistas para entender un fenómeno global, lo que nos lleva al concepto de paradigma. Lo anterior, entendido como modelos desde los cuales se originan tradiciones de investigación. En otras palabras, los supuestos fundamentales que tienen los investigadores sobre el universo observado ${ }^{3}$. Entre estas nuevas posiciones destaca una multiplicidad de relatos identitarios que cuestionan las unidades estatales tradicionales.

$\mathrm{Al}$ respecto, cabe consignar que a pesar de existir divergencias en los enfoques relativos a los cambios acaecidos, la comunidad de científicos sociales también presenta coincidencias. Entre ellas desta-

2 Brzezinski (1970) hablaba ya hace años de la sociedad tecnotrónica; McLuhan (1990), de la era de la electrónica o la aldea global; Toffler (1981), de la sociedad postindustrial o de la tercera ola; Torres (1994), se refería a la sociedad global y a las repercusiones a gran escala que tenían los nuevos mecanismos de comunicación. Castell (1994), refería a la sociedad informacional o información de la sociedad para caracterizar la naturaleza de este cambio". Véase Alex Caussa, Israel Rodríguez y Daniel López, "El conflicto en la sociedad red: la reivindicación de identidad y la lucha por el sentido"; Revista Persona y Sociedad; Vol. XVIII; N¹; Abril 2004; Universidad Alberto Hurtado; Chile.

3 La definición corresponde a Vásquez sobre la base de Kuhn. Véase Vásquez, John, El poder de las Política del Poder, México, Ediciones Guernica, $2^{\text {a }}$ Edición, 1992. 
ca una visión común respecto del surgimiento de doctrinas particularistas, el renacimiento de credos excluyentes y la aparición de nacionalismos militantes fomentados por la crisis de los paradigmas y de las grandes teorías de carácter universalista.

\section{Han surgido doctrinas particularistas, renacido credos excluyentes y} aparecido nacionalismos militantes.

Desde esta perspectiva, el sistema internacional vive una ampliación sin precedentes actualmente 1.92 Estados miembros de las Naciones Unidas pero también enfrenta tendencias a la fragmentación de algunas de sus unidades estatales, lo que ha provocado crisis humanitarias de envergadura.

La expresión más virulenta de esta fragmentación es la mayor frecuencia de conflictos armados intra-estatales en relación con los interestatales, especialmente en sociedades en que hay importantes focos de pobreza y marginalidad y en los cuales históricamente han existido demandas identitarias por parte de grupos religiosos o étnicos, tradicionalmente excluidos del goce de ciertos derechos.

En este trabajo intentaremos explorar cómo la noción de soberanía de ciertos Estados -elemento fundacional del sistema internacional moderno- se ha visto afectada por tensiones internas, que en conjunción con las tendencias globales externas ha provocado una sobrecarga de demandas por parte de sensibilidades étnicas y religiosas. Antes de ello, repasaremos algunas de las taxonomías propuestas para enfrentar las naturaleza de los conflictos de la post Guerra Fría.

\section{APROXTMACIONES A LOS}

\section{NUEVOS CONFLICTOS}

Al repasar algunas de las principales tipologías sobre los nuevos conflictos se puede abordar una definición menos particularista de los conflictos motivados por causas identitarias, enriquecida desde las distintas visiones y disciplinas sociales.

En cuanto a los conflictos armados intra-estatales, el proyecto Ploughshares intentá comprender los diversos tipos clasificándolos en varias categorías.

La primera de ellas, llamada de "conflictos por el control del Estado", agrupa a las luchas protagonizadas por los movimientos revolucionarios, las pugnas de las elites por la transferencia del poder y las campañas de descolonización ${ }^{4}$.

La segunda categoría comprende los "conflictos por la formación del Estado", que involucra a regiones de un país que pugnan por diversos grados de autonomía, ya sea mediante un referéndum o una secesión. En la actualidad, un gran número de conflictos son de este tipo y son representativos los casos de Sudán, India (por Cachemira), Sri Lanka (por los tamiles), Indonesia, Filipinas y los países que integraron la ex Yugoslavia.

4 En algunos casos, la religión (Argelia) y los intereses étnicos (Rwanda) juegan un papel central. En Fisas, Vincens, Cultura de Paz y Gestión de Conflictos, Barcelona, Icaria, 1998, p. 50. 
La tercera son los denominados "conflictos por el fracaso del Estado", en la que la pugna cristaliza tras la ausencia del control efectivo del territorio y la población por el gobierno. El error primario es una incapacidad para proveer seguridad humana mínima a la ciudadanía. Somalia sería un ejemplo de lo que sucede cuando se mezcla pobreza, ausencia de estructuras estatales y proliferación de armas ligeras. Un caso típico de lo que se ha denominado "Estado Fallido".

\section{El error primario es la incapacidad de} proveer de seguridad humana mínima a la ciudadanía.

No obstante, desde esta perspectiva, varios conflictos presentan elementos de dos o tres categorías a la vez, como los casos de Sudán, Irán, Irak o Filipinas.

Otra tipología es la elaborada por Doom y Vlassenroot, que distinguen cuatro tipos de conflictos: de legitimidad, de desarrollo, de identidad y de transición ${ }^{5}$.

Los conflictos de legitimidad son los que se relacionan con la fragilidad de los sistemas democráticos, ya sea por la escasez de participación política o por los problemas en la distribución del bienestar. Son conflictos típicos de las nuevas "democracias" en el hemisferio americano como Haití, Guatemala o Paraguay.

Los conflictos de desarrollo son aquellos que se gestan como consecuencia de la distribución desigual de los recursos por consiguiente, marcan una brecha entre los sectores boyantes de una sociedad frente a los que presentan precariedad.

Los conflictos de identidad se conforman a instancias de grupos que procuran proteger su identidad. Sus raíces se hallan en diferencias étnicas, tribales y lingüísticas que provocan disputas entre grupos, o entre un grupo y el poder central. En Europa central y la ex URSS han sido numerosos los conflictos de este tipo.

Los conflictos de transición se refieren a luchas entre fuerzas rivales, con diferentes intereses por alcanzar el poder en procesos de transición y cambio político.

Por su parte, Mohamed Sahnoun distingue cinco tipos de conflictos nuevos. En primer lugar, los de "carácter socioeconómico", que obedecen a la ausencia de democracia y a la desigual distribución de la tierra están en el fondo (Chiapas, etc.).

Los de "carácter religioso", que para este autor son una expresión de la manipulación ejercida por líderes políticos o religiosos para legitimar sus proyectos sociales. Sería el caso típico de Sudán, El Líbano, Chipre, los Balcanes, Mindanao filipino e Irlanda del Norte.

Enseguida cita las "crisis producidas por el fracaso de procesos de integración en la creación de los Estados-Nación", caracterizados por la ausencia de factores de unificación nacional, la falta de liderazgo y el monopolio de un grupo étnico (Chad, Zaire, Uganda, Rwanda, Burundi, Sri Lanka, Sierra Leona, etc.).

$s \quad$ Ver Doom, Ruddy y Vlassenrrot, Koen; "Early warning and conflict prevention. Minerva's Wisdom?"; Journal of Humanilarian Affairs, en internet: <www.jha.ac/articles/a022.htm>. 
Este autor cita también los conflictos llamados de "legado de la Guerra Fría", de muy difícil solución y que involucran una gran acumulación de armamento. Estos conflictos pueden tomar formas de guerra de liberación, como lo ocurrido en Angola, Mozambique, Camboya, Vietnam yAfganistán.

\section{Para Kissinger, un elemento importante del sistema político sería el legado colonial.}

Por último, las "crisis resultantes de la herencia colonial o de las dificultades de la descolonización, en los que suele haber disputas fronterizas y conflictos por la posesión de las tierras. Dentro de este tipo de conflicto las estructuras políticas todavía no alcanzan un Estado en plenitud, como los casos de Togo, los países del Cuerno de África, Cachemira, y la región del Cáucaso.

Sahnoun señala también factores de agravamiento como "la exportación de armas, interferencia exterior, ambición personal de los líderes individuales, insuficiencia de las estructuras administrativas, el debilitamiento de los mecanismos de conciliación indígena y la ausencia de una adecuada y rápida respuesta a las tragedias humanitarias".

Desde el neorrealismo de un autor como Kissinger, la expresión armada del conflicto es explorada a través de la tipificación de los subsistemas regionales del Medio Oriente y África. En el primer caso, el potencial explosivo de la región es comparado con los móviles de la historia europea del siglo XVII, es decir, con una dinámica de conflicto explicada a partir de la lucha religiosa, por lo que resulta difícil de aplicar la diplomacia tradicional para alcanzar un estado de paz. En cambio, respecto de África, el autor señala que difícilmente podría hacerse una analogía con la historia europea. En su opinión, los sistemas políticos no serían orientados por principios ideológicos, ni por el clásico concepto de equilibrio de poder. Mucho más relevante sería el legado colonial en un continente cuyas fronteras se superpusieron a identidades y culturas existentes. La combinación de conflictos étnicos, problemas de subdesarrollo y de salud ha generado un potencial desestabilizador que a menudo transforma guerras civiles en pugnas que sobrepasan los límites políticos de un Estado 7 .

Basándose en estas diferentes ópticas-que apuntan al incremento de las hostilidades armadas en los últimos añoscabe preguntarse si en alguna medida las actuales condiciones de globalización pueden haber influido en la expresión armadas de las dinámicas conflictuales.

6 Ver Sahnoun, Mohamed, "Managing Conflict in the post Cold War Era", conferencia pronunciada el 13 de octubre de 1995 en el Catholic for International Relations. En Fisas, Vincens, Op. Cit., p. 51.

7 Kissinger, Henry, Does America Need a Foreign Policy? Toward a Diplomacy for the 21 Century, Nueva York, Simon and Shuster Inc., 2001. 


\section{GLobalizaCión Y \\ FRAGMENTACIÓN POLÍTICA}

La globalización de los últimos 30 años es un fenómeno cualitativamente nuevo, consecuencia directa de la revolución de las tecnologías de información y de las comunicaciones, así como de la transnacionalización de las economías de mercado. Como muy bien señala la especialista Mary Kaldor, este proceso de intensificación de las interconexiones es un fenómeno contradictorio que implica a la vez integración y fragmentación, homogeneización y diversificación, globalización y localización ${ }^{8}$.

\section{La globalización sería consecuencia de la revolución de las TIC y de la} transnacionalización de las economías de mercado.

Una primera mirada a la globalización nos permite describirla esencialmente como el proceso mediante el cual se incrementan los vínculos transfronterizos entre diversos actores de la arena internacional, particularmente entre los Estados-naciones, las empresas multinacionales y, por cierto, organizaciones no gubernamentales, lo que se traduce en un grado de desdibujamiento de las fronteras internacionales. Sin embargo, las respues- tas de los actores institucionales y de las diversas sociedades nacionales van desde la exacerbación del proceso de globalización, lo que incide en el despotenciamiento de ciertos Estados-naciones más débiles, hasta el fortalecimiento del regionalismo, o incluso el despertar de nacionalismos.

Según Seyon Brown, en la actualidad hay falta de coherencia entre la estructura del sistema de Estados-naciones y otros aspectos que están integrando cada vez más la arena internaciona $1^{9}$. La persistencia de algunos de los más complejos problemas de la sociedad mundial contemporánea se relaciona con las instituciones, estructuras y normas de la política mundial estadocéntrica. Para Brown, la política mundial estaba rígidamente articulada en torno a la práctica del Estado-nación, lo que hoy le resta consistencia en un mundo cada vez más determinado por los diferentes grupos humanos en interacción más allá de las fronteras nacionales.

Las premisas básicas de la política mundial que por tres siglos dominó la lógica Gobierno/Sociedad era que la interacción humana tomaba lugar en jurisdicciones territorialmente definidas. Cacla una de estas unidades tenía su propio régimen de gobierno. La autoridad del régimen en su jurisdicción territorial era reconocida y respetada por otros Estados. Asimismo, el Estado soberano, representado por el gobierno, ejercía control sobre personas y

8 El argumento principal es que en los años ochenta y noventa se desarrolló un nuevo tipo de violencia organizada -especialmente en África y europa del Esle-, propia de la actual era de globalización. Véase Kaldor, Mary, Las Nuevas guerras, Barcelona, Tusquets Editores, 2001.

- Brown, Seyom, International Relalions in a Changing Global System, Boulder; Colorado Westeview Press, 1992. 
grupos al interior de su jurisdicción. En este marco las interacciones y transacciones internacionales estaban supeditadas en gran parte al control del Estado que actuaba mediante mecanismos de negociación y de guerra.

\section{Hay incongruencia entre el dinamismo de algunas entidades} y la rigidez de las instituciones y los gobiernos nacionales.

Existía correspondencia entre los deberes del Estado y sus derechos de soberanía. No obstante, en el mundo contemporáneo hay una gran incongruencia entre la movilidad dinámica de algunas entidades-como grupos, organizaciones $y$ grandes empresas - y la rigidez de las instituciones de los gobiernos nacionales ${ }^{10}$.

En esta tendencia se advierten las oportunidades y amenazas de una economía crecientemente transnacional para la política nacional. La cuestión central es que en el ámbito internacional el subsistema económico ha incrementado su poder y cruza sus propósitos con el ámbito político. Esta cuestión tiene varias aristas, entre las que figura la transnacionalización de las economías, que ejerce influencia colateral en aspectos como la cultura o la justicia social, el tráfico de productos, in- formación, capitales y personas es parte de este proceso.

Con respecto al globalismo económico, por primera vez en la historia se ha llegado a constituir un único sistema económico de alcance mundial. Este proceso de globalización económico y tecnológico ha contribuido a minar el papel del Estado-nación como el determinante del bienestar de la sociedad. Sin embargo, en ciertos "Estados centrales" -como Estados Unidos, Japón, o los países de Europa occidental-este fenómeno es menos evidente en la medida en que dichas sociedades han sido la fuerza conductora de su propio dinamismo. Simultáneamente, tampoco se puede olvidar que países como los del sudeste asiático -marginales durante la Guerra Fría- han optimizado sus potencialidades a partir de un proceso de inserción económica en los mercados mundiales.

Sin embargo, en contextos localesnacionales en que vastos tramos sociales quedan fuera de los circuitos económicos globales o representan eslabones subordinados en que no se desarrollan ventajas competitivas en la producción de bienes y servicios, complementados por el progresivo desmantelamiento de las funciones sociales del Estado, se ha debilitado la solidaridad grupal, provocando cierta inclinación hacia la fragmentación política. Fue la

10 Brown observa incongruencias de la estructura del sistema internacional de Estados-naciones (veasé Brown, Seyom, Op. Cit., pp. 115-127), en torno a cinco dimensiones:

1) Protección de valores comunilarios firente a la destrucción de la guerra.

2) La conducción de la economía internacional frente a la estructura política nacional.

3) Los sistemas ecológicos frente a las políticas públicas.

4) Las identidades culturales plurales frente a la lealtad al Estado-nación.

5) Los clerechos humanos frente a las normas jurídicas de los Estados. 
experiencia que siguió a la caída de ciertos Estados comunistas después de 1989.

La tendencia se acentúa en el caso de sociedades insertas en Estados fallidos cuyas referencias aluden principalmente a identidades tribales, de clanes, 0 religiosas. La progresiva pérdida de legitimidad de ciertos Estados postcoloniales en África en beneficio de las referidas identidades explica la constelación de guerras civiles entre grupos que antecedieron al establecimiento de fronteras nacionales elaboradas por las potencias europeas en el Congreso de Berlín de 1895.

De esta manera, los últimos años del siglo pasado estuvieron marcados, por un lado, por procesos de ampliación de los mercados, de asociaciones de libre comercio y por la emergencia de entidades de regulación comercial y, por otro, por una fragmentación geopolítica, que puede resumirse en la búsqueda de autonomía y la afirmación de identidades que se perciben amenazadas. Al decir de Rosenau, la globalización significó el desarrollo de cierta centralización de la economía de mercado y la consiguiente oposición de tendencias descentralizadoras manifestada por movimientos étnicos y nuevos nacionalismos"

Para Brown, las incongruencias de la política mundial también se relacionan con los conceptos modernos de nación y Estado. La cuestión central es que la correlación entre estos es cada vez más frágil como unidad fundacional de la política internacional. Diversas identidades cultura- les y etnias han impugnado la autoridad del Estado unitario del que formaban parte.

\section{La correlación de los conceptos de Estado y nación es cada vez más frágil como unidad básica de la política internacional.}

Por un lado, están los casos de los grupos étnicos, cuya distribución geográfica se reparte entre varios Estados y que aspiran a la activación del principio de las nacionalidades mediante el derecho de autodeterminación de los pueblos. Por otro, están los Estados que tienen jurisdicción sobre varias naciones, algunas de las cuales ya no le reconocen su soberanía.

Sin embargo, y a pesar de que diversos autores apuntan al debilitamiento de la soberanía -entendida como la capacidad de la autoridad reconocida para ejercer la dirección de los asuntos internos y externos de acuerdo con criterios y procedimientos libremente fijados a través de los propios procesos políticos, sin sujeción a ninguna otra potestad-por los fenómenos económicos de la globalización, no puede decirse lo mismo respecto de todas las formas de organización nacional. Si bien la específica declinación relativa de algunos Estados-naciones afectó la lealtad social a ciertos gobiernos nacionales, no puede sostenerse que se haya producido una simple disolución de los nacionalismos, 
regionalismos o localismos. Más bien, asistimos a la reafirmación de la diferencia por parte de nuevos movimientos sociales que enarbolan las banderas de la etnicidad o de una comunidad determinada. De esta manera, las tendencias universalizantes son impugnadas desde lo local, particular o específico, lo que una vez más retrovierte en la unidad del Estado-nación, que es sometido a presiones exógenas y endógenas.

\section{La globalización ha afectado de manera polimórfica los sistemas culturales de los países.}

Desde esta perspectiva, la globalización es una variable que podría incidir en la génesis y desarrollo de nuevos conflictos. La globalización ha afectado de manera polimórfica los sistemas culturales de los países. Las exclusiones provocadas por el paradigma dominante, en detrimento de sectores más vulnerables, ha provocado una creciente variedad de tensiones. De esta manera, algunas regiones y Estados se incorporan con dificultad a los beneficios de la globalización.
Al respecto, el incremento de la brecha entre los grupos sociales incorporados a los procesos transnacionales y los sectores excluidos puede repercutir en los consensos sociales establecidos para asegurar la cohesión política de las diversas comunidades. En dichos contextos, los equilibrios se hacen precarios, arriesgándose el respeto por las reglas de ley y orden. La ruptura acaece como resultado de la sensación de postergación histórica de un grupo que sociológicamente responde a la acepción de minoría $^{12}$.

Tampoco se pueden olvidar las diversas tensiones a que da lugar un proceso de globalización que se inclina por cierta desregulación:

- La tensión económica, producto de su dimensión altamente selectiva, jerárquica, que se traduce en la marginación relativa de ciertas regiones como el África ${ }^{13}$; la irregularidad de los circuitos y flujos comerciales, financieros y tecnológicos en el mundo.

- La tensión resultante de la dificultad de acceso a empleo, debido a que la aplicación de alta tecnología y cierta racionalidad de las técnicas productivas induce a una menor demanda de mano de obra en

12 Al respecto, véase Lechner, Norbert, "La política ya no es lo que fue", México, NEXOS, diciembre de 1995. Véase también Lechner, Norbert, "El Estado en el contexlo de la modernidad", en Lechner, Norbert et al., Reforma del Esiado y coordinación social, México, Plaza\&Valdés-UNAM, 1999.

13 En ese sentido, toda una vertiente de investigación promovida por diversos organismos internacionales-desde el Informe de Desarrollo Humano del Programa de las Naciones Unidas para el Desarrollo (PNUD) hasta los informes de la Conlerencia de las Naciones Unidas sobre Comercio y Desarrollo (UNCTAD)- coincide en que existe un grupo de países con niveles de desarrollo humano negativo que están más expuestos a las disputas polílicas y civiles propias de los conflictos armados, a serios desequilibrios socioeconómicos y a un debilitamiento de sus estructuras democráticas". En El estado de la paz y la evolución de la violencia, Centro Internacional de Investigación e Información para la paz, Universidad de Ia Paz de las Naciones Unidas, Uruguay, Editorial Trilce, 2001. 
los sectores industrial, de servicios y agrícola $^{14}$.

- La racionalidad de la productividad con carestía de empleo -o poco empleo en relación con las necesidades de la población-empuja a la gente a emigrar y a sobrevivir en forma irregular. Decenas de miles de personas se trasladan del campo a macrociudades cada vez más difíciles de administrar, pierden sus vínculos con bases agrícola-familiares de subsistencia y pasan a sobrevivir del circuito urbano de los trabajos marginales o de la criminalidad. Otros millones se desplazan de forma legal o ilegal de un país a otro buscando trabajar. Un creciente número de personas se integra a las redes del narcotráfico, o el tráfico de personas y la trata de blancas (asociada a la prostitución), la adopción ilegal de niños, o la venta de componentes nucleares de los poco controlados arsenales de la antigua URSS.

- La tensión cultural, provocada por la estandarización de una sociedad del consumo -difundida por los medios de comunicación masiva - a la que parte considerable de la población mundial no puede acceder. El ideal proyectado de países con instituciones de génesis democrática, de crecimiento económico sostenido, contrasta con el universo de autoritarismo, el auge de identidades particulares y fundamentalismos y el estancamiento y falta de oportunidades para satisfacer las necesidades humanas básicas ${ }^{15}$.

Algunas de estas tensiones alimentarán ciertos discursos contestatarios de comunidades marginales que articularán sus demandas contra la legitimidad de un Estado-nación específico. Sus proyectos políticos -de versiones secesionistas, emancipadoras, etc.- impugnarán el concepto de soberanía territorial, que articuló la práctica del "Estado Moderno" desde Westfalia en adelante. De esta manera, la soberanía estatal es globalización en el nivel internacional y de emergencia de la desafección de ciertos grupos que reclaman su autodeterminación y el derecho a la diferencia en el plano local. En este punto viene al caso repasar algunos aspectos del Estado moderno.

Las interacciones transnacionales surgidas de la globalización y los grupos que reclaman su autodeterminación ejercen presión sobre la soberanía Estatal.

Una definición genérica de Estado

Cada vez hay menos puestos de trabajo, pero en 2025 la población mundial llegará a los 8.500 millones de personas. Esto significa que nacerán alrededor de 98 millones al año, el $95 \%$ de ellas en el denominado Tercer Mundo. En la actualidad, la población de Jos países considerados "menos adelantados" constituye el $13 \%$ de la población mundial.

15 "Los paradigmas finiseculares no pueden obviarse a la hora de intentar reconocer y descubrir los conflictos. Fred Halliday resume tres grandes vectores de la época actual: un orden mundial desordenado tras la imprecisión de los liderazgos internacionales, la abdicación de la política tras el divorcio de esta con la economía y la aceleración de la mundialización tras la crisis del Estado-Nación". En Halliday, Fred, El estado de la paz y' la evolución de la violencia, Centro Internacional de Investigación e Información para la paz, Universidad de la Paz de las Naciones Unidas, Uruguay, Editorial Trilce, 2001. 
debe atender a que se trata de una entidad jurídica y política, resultado de la vigencia de un poder soberano sobre una población específica en un territorio determinado. Desde una perspectiva weberiana, se trataría de una asociación institucional que sobre un territorio específico ejerce el monopolio de la coacción y detenta la legitimidad de sus acciones. Es decir, se trata de un sistema que regula las relaciones sociales al interior de una comunidad a través de la persuasión, el derecho o la fuerza si fuera necesario, pese a que, históricamente, se ha asistido a diversas formas de Estados: las polis griegas, la república romana o el califato musulmán.

Como sabemos, el modelo particular de Estado-nación moderno corresponde al tipo cultural específico de ordenamiento político europeo occidental. Dicho significado fue históricamente determinado desde el tránsito de la estructura política policéntrica de la Edad Media hacia una modalidad de Estado patrimonial asociado a una dinastía monárquica en el siglo XIII. Posteriormente, el patrimonio regio adquirió consistencia territorial en los siglos XIV al XVI, con lo cual el soberano príncipe reinó sobre los habitantes de un territorio determinado. Cuando el grupo humano adquirió conciencia de su especificidad (diferencia hacia fuera y semejanza hacia su interior) y de que estaba indisolublemente unido a un territorio, nos encontramos en la etapa de formación del Estado nacional, que pasará a ser "mo- derno" cuando sus "nacionales" comiencen a exigir mayores márgenes de participación en los asuntos públicos.

De esta forma, el Estado-nación moderno se asociaba al "principio de nacionalidades" que consagró teóricamente el derecho de toda nacionalidad a dotarse de una organización política propia. En un desarrollo posterior, dicho principio dio paso al derecho de autodeterminación de los pueblos, que intentó legitimar el principio de las nacionalidades mediante la práctica democrática. Bajo esta dinámica, esencialmente "moderna", emerge el concepto de gobierno representativo.

En un contexto de erosión de la autonomía del Estado, es decir, de erosión del monopolio de la violencia legítima, surge una nueva generación de conflictos arma$\operatorname{dos}^{16}$. Aunque la post Guerra Fría tuvo un momento inicial pletórico de visiones optimistas que vaticinaban una mayor estabilidad del sistema mundial, seguida de una caída del número de conflictos armados internacionales, la experiencia indica exactamente lo contrario: más guerras cualitativamente diferentes.

\section{Los Estados Unidos y la URSS eludieron una colisión frontal y desplazaron el conflicto a la periferia.}

Durante la Guerra Fría, tanto Estados Unidos como la URSS tuvieron como objetivos la expansión de sus ideologías y la consolidación de sus posiciones geoestra-

16 No existe consenso entre los científicos sociales sobre un concepto único, se les ha denominado, entre otras maneras, de conflictos de nuevo tipo, nuevas guerras, amenazas emergentes, etc. 
tégicas. Ambas potencias eludieron una colisión frontal, desplazando el conflicto a la periferia, mediante la utilización de países aliados fuera de sus áreas neurálgicas (territorio estadounidense, soviético y europeo) como instrumento de desestabilización de la potencia adversaria. Aunque evitó una conflagración mundial legó a la post-guerra un conjunto de Estados altamente militarizados y, en ocasiones, de institucionalidad demasiado débil como para hacerse cargo de conflictos no resueltos (Angola, Mozambique, Somalia, Afganistán, entre otros) ${ }^{17}$.

Respecto del otro concepto de la díada, el de "nación", su supuesta invariabilidad histórica también ha quedado en suspenso, en la medida en que diversas aproximaciones han enfatizado las transformaciones graduales que toda sociedad experimenta. Aunque cada nación se compone de elementos como la lengua y la religión, cuya modificación implica procesos de largo aliento, su configuración es histórica. Es decir, una nación es la expresión histórica de distintas aportaciones culturales que en un proceso gradual han generado una identidad. $\mathrm{Al}$ respecto cabe consignar que la formación de las identidades involucra procesos de selección, evaluación, naturalización y oposición ${ }^{18}$. En este último caso, irrumpe la alteridad como cuestión central, el "otro" para definir al grupo nacional. Al decir cle Giddens: "El principio de nacionalidades descansa sobre una serie de postulados. Las identidades nacionales son una fuente válida de identidad personal; los individuos que experimentan ser parte de una nación como elemento de su identidad no sufren una ilusión (...) Las naciones son comunidades éticas, en las que aquellos incluidos en ellas tienen ciertas obligaciones respecto a los otros miembros que no siempre son reconocidas frente a personas de afuera. Las naciones proporcionan un foco para la autodeterminación"19.

\section{El fin de la Guerra Fría permitió que afloraran conflictos étnicos, confesionales y sociales latentes.}

\section{LA POLÍTICA DE IDENTIDADES EXCLUYENTES}

En los años noventa, muchos de los conflictos emanados de la reivindicación de la diferencia cultural adquirieron una dimensión violenta. En otras palabras, el fin de la Guerra Fría permitió que afloraran conflictos étnicos, confesionales y sociales que se habían mantenido latentes, pro-

17 En su libro La transformación de los conflicıos, Jean Rufin señala que los últimos años de la Guerra Fría, denominados de "inseguridad controlada", se caracterizaron por la existencia cle guerras de baja intensidad y profusión de guerras de guerrillas. Citado por Fisas, Vicens, Op. Cit., p. 40. Larraín, Jorge, Modemidad, Razón e Identidad en América Latina, Santiago de Chile, Editorial Andrés Bello, pp. 210-211. Giddens, Anthony, La Tercera Vía. La renovación de la Socialdenocracia, Madrid, Taurus Ediciones, $2^{\mathrm{a}}$ edición; 1999; pp. 155-156. 
ducto del orden colonial y después del impuesto por las grandes potencias.

Pero también surgieron nuevos conflictos producto de fenómenos de dislocación, de fragmentación, ya sea en regiones o zonas que exigían mayor autonomía política o autogobierno, o la preeminencia de una determinada religión, proceso que se agudiza ante la marginación de los beneficios del desarrollo económico social.

Estos nuevos conflictos no pueden explicarse completamente usando modelos o patrones de interpretación del pasado, sea por la morfología que adopta la violencia, por su carácter interno o por su inesperada emergencia en cualquier punto del planeta.

Para Samuel Huntington, la caída de la cortina de hierro dio paso a un "telón de terciopelo" que separa a las civilizaciones en conflicto. El autor anunció un choque de civilizaciones intenso, "puesto que las diferencias culturales (en su opinión) marcan distancias insalvables entre los individuos, los que ya no buscarán su identificación primaria en la nacionalidad, sino en su religión, lengua y costumbres particulares"20. Por otro lado, Hans Enzensberger planteó el concepto de "guerra civil molecular" planetaria, expresada en ámbitos urbanos y vinculados a subculturas de tipo marginal ${ }^{21}$.
En la perspectiva de Mary Kaldor, los nuevos conflictos (nuevas guerra en su concepto) surgen en el referido contexto de debilitamiento de la autonomía y autoridad del Estado, producto del fin de la Guerra Fría, reflejando el vacío de poder típico de los períodos de transición en la historia mundial. Para Kaldor, el monopolio del uso de la fuerza legítima está debilitado por la transnacionalización de las fuerzas militares. La capacidad de los Estados de usar la fuerza de modo unilateral contra otros está muy debilitada. Es difícil pensar en un Estado o grupos de Estados que se arriesguen a una guerra en gran escala que, sin duda, sería la más destructiva que la humanidad pudiese vivir.

\section{La transnacionalización de las fuerzas militares debilita el monopolio del uso de la fuerza legítima.}

Para Kaldor, el contraste entre las guerras antiguas y las nuevas se da en relación con sus objetivos, métodos de lucha y modos de financiación. Principalmente, porque los objetivos de estas nuevas guerras están relacionados con las políticas de identidades exclusivas, a dife-

Huntington Samuel, Choque de civilizaciones, Barcelona, Ediciones Paidos, 1997.

"Se trata de un tipo de conflicto sin objetivos políticos claros, con un alto grado de violencia y, en ese sentido, el ensayista alemán advierte que cualquier vagón de subterráneo puede convertirse en una Bosnia en miniatura. La configuración de ese nuevo tipo de conflictos posee el agravante de que no están regulados por el derecho internacional, ya que ocurren en el seno de los Estados, por lo que la aplicación del derecho humanitario se hace impracticable". En El estado de la pazy la evolución de la violencia, Centro Internacional de Investigación e Información para la Paz, Universidad de la Paz de las Naciones Unidas, Uruguay, Editorial Trilce, 2001. 
rencia de los objetivos geopolíticos o ideológicos de las guerras anteriores. Se trata de una política de identidades que enfatiza la resistencia a que un grupo sea subsumido en un orden nacional o incluso en un sistema internacional. Mediante la política de identidades se reivindica el poder descle la especificidad cultural de un discurso que enfatiza la pertenencia a un grupo nacional, un clan o incluso a una religión.

\section{La idea de cambio se vincula} con una representación simbólica del pasado idealizado.

Lo anterior no significa que hayan desaparecido las ideas sobre el cambio económico o social, sino que la idea de cambio está estrechamente vinculada a una representación simbólica del pasado idealizado. De esta manera, el discurso de la política de identidades aprovecha el fracaso o la disolución de otras narrativas políticas para recuperar la memoria y reconstruir las tradiciones particularistas. Lo anterior permite aseverar que se trata de un desplazamiento pretérito a identidades premodernas, temporalmente suprimidas por la imposición de diversas variantes del proyecto modernizador, particularmente en sus aspectos de centralismo político y universalismo jurídico.

Sin embargo, lo que hace nuevo este tipo de respuesta local es que es simultáneamente planetaria. Las exigencias nacionales se transnacionalizan mediante el uso intensivo de las nuevas tecnologías de comunicación. La irrupción en los medios de comunicación del Ejército Zapatista de Liberación Nacional el $1^{\circ}$ de enero de 1994 es un caso concreto de posicionamiento de una demanda local en la agenda pública mundial. La acelerada difusión de las ideas a través de las fronteras nacionales y el tratamiento de los datos son consecuencias directas de las tendencias globalizadoras. El resultado es que en vez de producirse la homogeneización cultural se incrementa la fragmentación.

Los proyectos de reafirmación de la especificidad y de la diferencia pueden tornarse francamente excluyentes si están respaldados por una retórica de oposición virulenta a la alteridad inmediata. En dichos casos, sus discursos y prácticas abandonan las demandas de reconocimiento de sus diferencias por medio del particularismo jurídico para abogar y orientarse a un exclusivismo identitario.

\section{LAA VARIANTE RELIGIOSA}

Hacia fines del siglo XX, el renacimiento religioso se constituyó en un fenómeno presente en el quehacer social y político de diversas sociedades. Muchas de ellas han aprobado la separación del Estado, optando por el procesamiento de las diferencias con la autoridad mediante su partícipación pública dentro del marco legal. Sin embargo, hubo algunas experiencias que enfatizaron la dimensión conflictiva dentro de diversas sociedades.

Al respecto cabe señalar que ciertos credos religiosos han contribuido notablemente a la formación de una nación o a la emergencia de ciertos nacionalismos. 
Otras corrientes religiosas, presentes en el Islam y en algunas expresiones históricas de ciertas tradiciones cristianas, enfatizan las tendencias universalistas y antinacionalistas. Complementariamente, se puede afirmar que el cristianismo ha sido en Europa un modelador de naciones que, como resultado de un proceso posterior de institucionalización, se organizaron en torno a Estados 22 .

En la actualidad se han desarrollado corrientes religiosas que enfatizan el retorno al origen o el regreso a una etapa determinada en la evolución de una comunidad religiosa. Es el caso de los rigorismos o los radicalismos religiosos. Frente a la imposición de modelos políticos culturales externos algunos grupos han enfatizado la reconstrucción de un sistema cultural premoderno. También se trata de una recuperación del pasado orientado por la reedición de culturas antiguas horizontales con un alto grado de sofisticación administrativa, basadas en un código valórico religioso y no necesariamente unidas -aunque tampoco se descarta- a un Estado. Los contemporáneos radicalismos religiosos cultivan la función de resistencia en la actualización de dichos proyectos.

Cabe consignar que las versiones del fenómeno del radicalismo religioso han desembocado tanto en formatos subculturales de corte antisistémico de contornos violentos, como en otras vertientes que han adoptado un perfil sectario, que propugna un abierto pacifismo separatista. Al respecto, cabe recordar que aunque a menudo se comprueba que las religiones crean y aplican mecanismos de solución pacífica de los conflictos, también existe evidencia en el sentido contrario, es decir, una determinada creencia religiosa justifica, cuando no fomenta, la solución no pacífica de los conflictos ${ }^{23}$.

El radicalismo religioso se ha expresado en formatos antisistémicos y en vertientes que propugnan un
pacifismo separatista.

La propensión a la administración violenta o pacífica de los conflictos depende de la forma en que se articula un proyecto religioso determinado y su entorno sociopolítico. Así, una forma religiosa puede respaldar y legitimar un sistema nacional/internacional (función integradora), o antagonizar, favoreciendo la morfogénesis sistémica (función transformadora). En el primer caso, la función integradora opera como factor de legitimación de un deter-

22 Adrián Hastings lleva al extremo el argumento que identilica al cristianismo con la construcción de naciones al afirmar que: "La nación y el nacionalismo son característicamente cristianos y, siempre que han aparecido en otras partes, lo han hecho dentro de un proceso de occidentalización y de imitación del mundo cristiano, incluso si ha sido imitado en su calidad de occidental y no de cristiano". Véase Hastings, Adrián, La construcción de las nacionalidades, Cambridge, Cambridge University Press, 1997, 2000, p. 230.

23 Véase Molina, Beatriz y Cano, María José, "La Paz desde la Diversidad Cultural y Religiosa" en Muñoz, Francisco, La Paz Imperfecta, Granada, Editorial Universidad de Granada, 2001, p. 162. 
minado orden, mientras que en el segundo se orienta a la transformación de las condiciones de un sistema que considera ilegítimo ${ }^{24}$. De esta manera, tanto en la regulación pacífica de los conflictos como en el ejercicio de la violencia influye el tipo de relación que establece una religión con la autoridad pública.

\section{La relación entre la religión y la autoridad pública influye en la regulación pacífica de los conflictos} y en el ejercicio de la violencia.

En la actualidad, el radicalismo religioso de corte violento presenta las siguientes características:

- Se asocia principalmente al islamismo radical, aunque con ciertas expresiones marginales en el radicalismo protestante (ideología de la identidad cristiana) y el radicalismo reljgioso judío (movimiento kahanista).

- Para sus adherentes, la violencia indiscriminada tiene un sentido sacramental.

- Persigue cambios radicales, aunque a menudo utiliza las ventajas tecnológicas de la globalización de las comunicaciones.

- Comprende identidades de resistencia que se oponen a occidente o a los valores de la modernidad.

Hay que enfatizar que el radicalismo religioso no se relaciona en forma unívoca con el ejercicio de la violencia política. Su identidad distintiva se caracteriza por la voluntad de imponer una verdad revelada (sagrada) en forma absoluta (exclusivismo sectario) sobre un grupo humano que percibe amenazada su identidad ante el avance de la secularización (en el caso del radicalismo religioso cristiano) o alejado de los principios fundamentales de la cultura religiosa (como consecuencia de una modernidad que, en el caso islámico, equivale a occidentalización).

Durante una fase germinal, la violencia se canalizará contra la dirigencia local nacional, considerada corrupta, aunque luego pueda escalar a un enfrentamiento total contra quienes considera enemigos globales del proyecto sociopolítico (globalización del adversario). En las organizaciones religiosas radicales de ideología transformadora, que aplican una estrategia de acción trasnacional y tienen capacidad de reclutar militantes de la causa en amplias bases sociales, se observa un fuerte impulso por acceder al plano internacional, en competencia -y en ciertos casos hostilidad-con los Estados. De lo anterior se desprende que la participación del radicalismo religioso en la esfera internacional es mediatizada por su capacidad de influir en los segmentos de la sociedad civil que no están de acuerdo con el sentido del actual proceso de globalización.

Aunque el radicalismo islamista no tiene la exclusividad de la violencia, presenta una novedad en cuanto al alcance de 
sus objetivos. Como resultado de la rivalidad con los países europeos en áreas de frontera cultural o de la hostilidad hacia la presencia de cuerpos armados internacionales en sus territorios, el islamismo radical ha dado un salto cualitativo, transnacionalizando su estrategia de enfrentamiento con los "poderes occidentales", bajo el signo del yihadismo global. A ello apuntan a los atentados de 11.09.01 y 11.03.04.

\section{El islamismo radical se ha traducido en un antagonismo frente a la hegemonía occidental.}

Antes, la primera generación de islamistas radicales (década del veinte $y$ treinta del siglo $\mathrm{XX}$ ) se rebeló contra los representantes de los gobiernos nacionales en tierras islámicas. Posteriormente, han escalado hacia un antagonismo frente a la que consideran hegemonía occidental en el orden internacional. En el primer caso se trataría de conflictos de dinámica local-nacional, contra una autoridad política percibida como ilegítima (Israel en el caso de los islamistas palestinos) o contra un gobierno dirigido por musulmanes considerados corruptos por los islamistas (como en el caso de Argelia). En el segundo caso responde a una visión maniquea entre el Islam y occidente que enfatiza la confrontación a escala global. Dicha perspectiva corresponde a la ideología yihadista transnacional del tipo de $\mathrm{Al}$
Qaeda, y de Jemmah Islamiyah en el sudeste asiático. Estas expresiones han incrementado el número de conflictos internacionales contemporáneos.

\section{LOS CONFLICTOS ARMADOS CONTEMPORÁNEOS}

A pesar de las tendencias mencionadas, es posible constatar que actualmente en los Estados - protagonista institucional en que ocurren los conflictos-más estructurados, cuya situación económica y sistema político es estable no hay guerras o conflictos armados intermedios o mayores. Pero los Estados Frágiles -esto es, aquellos que no han logrado consolidar sus instituciones, en especial si se trata de Estados de regiones marginales del sistema mundial o de los circuitos económicos más dinámicos- son los que más enfrentan situaciones de conflicto armado. Desde esta perspectiva, se puede enfatizar que actualmente la mayoría de los conflictos son de carácter intraestatal y no interestatal, aunque puede llegar a afectar a más de una unidad estatal.

Como señala el Instituto de Investigación para la Paz de Estocolmo (SIPRI ${ }^{25}$, salvo dos excepciones, en los últimos años la mayoría de los conflictos armados importantes han tenido lugar al interior de los Estados. De los 101 conflictos armados ocurridos entre 1989 y 1996 , solo seis fueron interestatales, y los 95

2s Harris, Peter, Democracia y' conflictos profundamente arraigados: opciones para la negociación, International Institute for Democracy and Electoral Assistance, Bogotá, Tercer Mundo Editores, 2001 , p. 10. 
restantes se produjeron dentro de los Estados.

\section{Cuando no hay consenso para abordar el desarrollo político y social se producen pugnas violentas por el poder político.}

Los antecedentes inmediatos de la lucha armada en estos conflictos se relacionan con el control del gobierno y del territorio. Grupos sociales, étnicos y políticos intentaron controlar un Estado o provocar su escisión (como los casos de Angola, Camboya, etc.). Asimismo, hay pugnas violentas por el poder político cuando no existe consenso en las elites para abordar el necesario desarrollo político y social (Haití, la rebelión de Chiapas en México). Esta situación se torna más compleja cuando las demandas de la base social ante las elites son asumidas por radicalismos religiosos que cuestionan las bases culturales de un Estado nación moderno de sabor "occidentalizante" (acusación que hacen los islamismos violentos y militantes de Argelia) ${ }^{26}$.

Por otra parte, hay casos en que grupos sociales que se centran en torno de una etnia o religión tratan de controlar territorios que consideran que les pertenecen históricamente y en los que a veces habitan ciudadanos de su misma etnia. Fue la experiencia de Serbia en Bosnia, y la de Rusia y las minorías rusas que viven en diversas repúblicas de la antigua Unión Soviética.

En el caso de Europa, 15 de los 18 conflictos registrados entre 1989 y 1993 se situaron en la antigua Unión Soviética y en la ex Yugoslavia. De los 27 conflictos clasificados en 1999 como conflictos armados importantes (con más de mil muertos al año), 26 tuvieron un inequívoco componente identitario ${ }^{27}$.

Uno de los mayores desafíos del fin de siglo se encuentra en estos conflictos cuyas causas económicas y sociales profundas podrían homologarse, pero que adquieren una enorme complejidad al identificarse sus actores con signos religiosos, étnicos o nacionalistas.

Las características de los actuales conflictos armados y los cambios acaecidos en el contexto internacional permiten definirlos como conflictos "profundamente arraigados". Estos conflictos se originan principalmente al interior de los Estados y combinan dos poderosos elementos: un importante componente de identidad basado en las diferencias de raza, religión, cultura o idioma o cualquier otro rasgo de identificación de un grupo o comunidad, y un desequilibrio percibido en la distribución de los recursos económicos, políticos y sociales.

Las experiencias de conflictos armados post Guerra Fría nos muestran que durante el esquema bipolar se mantuvo latente un alto grado de hostilidad étnica, reivindicación de Tíbet ante China 
debido -fundamentalmente- al rol regulador que ejerció la ex Unión Soviética, basado más que nada en la represión de estos mismos conflictos. Una vez que se produjo el desplome de la potencia, los grupos de identidad se sintieron compitiendo en un juego de suma cero por los recursos o el territorio. Pero, también, muchas veces las cuestiones de identidad se convirtieron en un pretexto muy útil para encubrir incompatibilidades relacionadas con la distribución de los recursos, en algunos países más escasos, producto de lo selectivo de la globalización. Fue el caso de numerosos conflictos en África, cuyo detonador han sido intereses económicos más que ideológicos: la posesión de las minas de diamantes.

Pero no siempre las reivindicaciones de identidades culturales o étnicas son negativas. La identidad puede ser tanto una fuerza constructiva como desestabilizadora. Muchas de las sociedades multiculturales actuales -Estados Unidos, Canadá, Australia - han basado su éxito en la conjunción positiva de las diferentes culturas y religiones que la componen. Sin embargo, en estos países conllevan un nivel de desarrollo económico importante, producto de los beneficios que les ha entregado la globalización. En otros lugares del planeta, comunidades compuestas por distintas tradiciones religiosas o culturales -como el caso de Bélgica, Mauricio o Trinidad y Tobago- han demostrado ser capaces de procesar los elementos conflictuales en sus sistemas políticos y econó- micos para potenciar la sana convivencia de sus diferentes grupos ${ }^{28}$.

\section{Las reivindicaciones de identidades culturales y étnicas no siempre son negativas.}

Si bien siempre cabe la posibilidad de que estas diferencias se presten para la manipulación política por parte de "oportunistas étnicos", que tratan de movilizar y aprovechar para su propios intereses la diversidad, la explotación sólo tendría éxito en contextos específicos: factores económicos que perpetúan la pauperización de las condiciones de vida de amplios estratos de la población o factores culturales como derechos lingüísticos y libertades religiosas conculcados. A su vez, los medios de comunicación masiva abren posibilidades de colocar en un ágora pública-global las demandas particularistas, incidiendo en la reafirmación de la diversidad latente o incipiente al interior de una unidad nacional. En dichos contextos, la expresión de la autodeterminación a menudo viene dada por la reivindicación de la secesión total.

\section{AlguNAS CONSIDERACIONES}

Se puede constatar que el fenómeno de la globalización ha afectado las formas de representación de actores cuya referencia ya no está anclada al ámbito del 
Estado-nación. Lo anterior importa un cambio en la unidad de análisis en el estudio de las relaciones internacionales que observa la emergencia de ciertos grupos subnacionales en la arena internacional. La desafección de ciertos grupos a los relatos de cohesión estatal que negaron la expresión histórica de ciertos rasgos de identidad, o la pauperización de las condiciones de vida como resultado de tendencias económicas globales, se actualiza bajo la forma de conflictos que pueden llegar a escalar a un estado armado.

\section{Los límites de un Estado rara vez corresponden a aquellos de un grupo de identidad.}

La expresión de los conflictos armados identitarios tiene una dimensión internacional muy relevante. Los límites de un Estado, en particular en las sociedades postcoloniales, muy raramente corresponden a los de una "nación" -grupo de identidad-por lo que es muy extraño que el conflicto interno se mantenga dentro de las fronteras estatales. Un repaso de la mayoría de los conflictos armados actuales nos permiten señalar que hay terceros países que son actores principales de ellos: Sri Lanka (India), Irlanda del Norte (Reino Unido, República de Irlanda y comunidad irlandesa en Estados Unidos), Chipre (Turquía y Grecia), Sahara (Francia, España y Marruecos), entre otros.

Los problemas centrales del manejo o transformación de conflictos profundamente arraigados basados en la identidad radican en su "indivisibilidad", ya que no suelen ser proclives a soluciones que contengan compromisos que incluyan concesiones equitativas para compartir el poder. Por esto, los conflictos basados en identidades históricas, creencias religiosas, idioma o posesión de territorios simbólicos son especialmente difíciles de manejar. Al respecto cabe consignar lo particularmente difícil de llegar a un consenso que se exprese constitucionalmente sobre cuestiones de carácter teológico o si un lugar sagrado debe pertenecer un grupo o a otro.

Enseguida, hay que considerar la naturaleza cíclica de muchos conflictos profundamente arraigados. Las acciones de un grupo son respondidas aceleradamente con las de su oponente: la violencia provoca más violencia, con lo cual el conflicto escala progresivamente a un intercambio de ajustes de cuentas. Las reivindicaciones originales se ven amplificadas y, a menudo, sustituidas por nuevas y más exageradas, surgidas durante la dinámica de escalada. Estos temas se pueden prestar a la manipulación de ciertos liderazgos políticos que pueden hacer uso de ellas para movilizar a las comunidades, con lo que resulta difícil romper un patrón histórico.

Dichas características hacen que los conflictos profundamente arraigados - post Guerra Fría-sean de muy difícil solución, careciendo los organismos internacionales de los instrumentos necesarios que permitan su adecuada prevención.

Por el contrario, en la mayoría de los casos los conflictos profundamente arraigados han escalado peligrosamente, tanto en frecuencia como en intensidad hacia 
un peligroso umbral de confrontación militar, que una vez desatada solo puede ser contrarrestada por la imposición de la paz.

Retomando a Beck, estas identidades pueden ser catalogadas como nacionalismos introvertidos que están a la defensiva frente a la que consideran invasión del mundo global. En ciertas ocasiones, la respuesta nacionalista puede ser el atrinche- ramiento en posiciones irreductibles que ya no solo se orientan contra la unidad estatal inmediata sino contra los Estados centrales del sistema internacional, que identifican como los conductores del proceso globalizador: De estos nacionalismos interiores puede surgir una intolerancia proclive a la violencia que puede dirigirse contra todos. 